\title{
Grandes inundaciones en la ciudad de Murcia a través de la documentación histórica: medidas de defensa y contexto socioeconómico
}

\author{
Major floods in the City of Murcia through historical \\ documentation: defence measures and socioeconomic context
}

Grans inundacions a la ciutat de Múrcia a través

de la documentació històrica: mesures de defensa

i context socioeconòmic

Salvador Gil-Guirado ${ }^{1}$

Jorge Olcina Cantos ${ }^{2}$

Alfredo Pérez-Morales ${ }^{3}$

\section{Resumen}

El estudio de inundaciones históricas ha generado en los últimos años metodologías que persiguen transformar la información cualitativa contenida en la documentación histórica en información cuantitativa. Sin embargo, la diversidad de los contextos culturales e históricos, así como la heterogeneidad de las fuentes documentales, dificulta la capacidad de extrapolación de los métodos cuantitativos en climatología histórica. Esta situación favorece que los análisis hermenéuticos de textos sigan siendo un elemento esencial en el estudio del clima pasado. Este trabajo realiza un análisis de estas características sobre las tres inundaciones más catastróficas ocurridas en la ciudad de Murcia en los últimos cuatrocientos años. Se destaca el hecho de que la sociedad murciana tenía estrategias de superación de catástrofes que involucraban al conjunto de la sociedad y preconizaban una gestión integral de las emergencias. No obstante, el estado de penuria económica previo a una inundación es un factor determinante para explicar la capacidad de resiliencia del sistema social. Es, asimismo, relevante el gran aumento de la exposición a zonas inundables producido en los últimos dos siglos, con ocupación progresiva del espacio de huerta tradicional para usos no agrarios que se mantiene hasta la actualidad. Se puede afirmar que la sociedad

1. ORCID: 0000-0002-3486-7476. Universidad de Murcia. Correo electrónico: salvador.gil1@um.es.

2. ORCID: 0000-0002-4846-8126. Universidad de Alicante.Correo-e: jorge.olcina@ua.es.

3. ORDIC: 0000-0001-7532-8711. Universidad de Murcia.Correo-e: alfredop@um.es.

Recibido: 04/2021. Evaluado: 07/2021. Versión definitiva: 08/2021 
murciana preindustrial usaba de forma más eficiente los mecanismos de los que disponía para adaptarse a las inundaciones.

Palabras clave: inundaciones históricas, fuentes documentales, ciudad y Huerta de Murcia, cartografía histórica, vulnerabilidad, exposición al riesgo de inundación.

\begin{abstract}
In recent years the study of historical floods has generated methodologies aiming to transform the qualitative information contained in the historical documentation into quantitative information. This coding process seeks to make the way in which societies adapted to floods in the past understandable and comparable in time and space, to extract positive or negative points that can help reduce vulnerability and increase the resilience of today's societies. The diversity of cultural and historical contexts, as well as the heterogeneity of documentary sources, makes it difficult to extrapolate quantitative methods in historical climatology. This situation favors the fact that hermeneutical analyses of texts continue to be an essential element in the study of the climate of the past. This paper carries out a hermeneutical analysis of the three most catastrophic floods that occurred in the city of Murcia in the last 400 years. We complete this analysis with a quantitative historical cartographic reconstruction. As a main conclusion, Murcian society had strategies for overcoming disasters that involved the whole of society and that advocated comprehensive management of emergencies in particular. However, the state of hardship prior to a flood is a determining factor to explain the resilience capacity of the social system. At the same time, the great increase in exposure to flooded areas in the last two centuries is noteworthy, with progressive occupation of the traditional orchard space for non-agricultural uses that continues today. It is possible to affirm that pre-industrial Murcian society more efficiently used the available mechanisms to adapt to flood events.
\end{abstract}

Keywords: Historical floods, documentary sources, city and orchard of Murcia, historical cartography, vulnerability and exposure to flood hazard.

\title{
Resum
}

L'estudi d'inundacions històriques ha generat en els darrers anys metodologies que busquen transformar la informació qualitativa continguda en la documentació històrica en informació quantitativa. Tot i així, la diversitat de contextos culturals i històrics, així com l'heterogeneitat de les fonts documentals, dificulta la capacitat d'extrapolació dels mètodes quantitatius en climatologia històrica. Aquesta situació afavoreix que les anàlisis hermenèutiques dels textos continuïn essent un element essencial en l'estudi del clima del passat. Aquest treball du a terme una anàlisi d'aquestes característiques sobre les tres 
inundacions més catastròfiques que han tingut lloc a la ciutat de Múrcia en els darrers quatre-cents anys. Es destaca el fet que la societat murciana tingués estratègies de superació de catàstrofes que involucraven al conjunt de la societat i preconitzaven una gestió integral de les emergències. Així i tot, l'estat de penúria econòmica previ a una inundació és un factor determinant per explicar la capacitat de resiliència del sistema social. És, així mateix, rellevant l'augment de l'exposició a zones inundables produit en els darrers dos segles, amb ocupació progressiva de l'espai d'horta tradicional per a usos no agraris que es manté fins a l'actualitat. Es pot afirmar que la societat murciana preindustrial feia servir de forma més eficient els mecanismes de què disposava per adaptar-se a les inundacions.

Paraules clau: inundacions històriques, fonts documentals, ciutat i Horta de Múrcia, cartografia històrica, vulnerabilitat, exposició al risc d'inundació.

\section{Introducción. La importancia de las fuentes documentales para el estudio detallado de riesgos históricos}

La relación entre una sociedad y su medio a lo largo de la historia componen un proceso caracterizado por constantes fricciones y desequilibrios que desencadenan impactos traumáticos. Estos desequilibrios generan situaciones de riesgo. Sin embargo, la complejidad y multidimensionalidad de los factores que intervienen en los procesos de creación de territorio de riesgo ha provocado acercamientos a su estudio desde enfoques diversos que han causado desajustes conceptuales y de método en torno a la propia definición del riesgo natural. Así, el concepto «riesgo» es concebido de forma diferente por los investigadores en función de su formación y de la corriente epistemológica que se practique. Mientras que algunos lo plantean como resultado de un producto matemático, capaz de ser modelizado y medido en unidades, otros señalan que la condición de riesgo, como creación básica por parte del ser humano, no tiene sentido fuera de la esfera de lo perceptual y lo social. Estas dos tendencias se evidencian por medio de las definiciones dadas del concepto de riesgo. Por el lado de la vertiente cuantitativa, las definiciones de riesgo natural se centran en su carácter cuantificable. Villevieille (1997) señala que el riesgo es el producto matemático de la probabilidad de ocurrencia de un evento peligroso y de la estimación de daños susceptibles a causa de este. Pita y Olcina Cantos (1999) destacan el riesgo como un fenómeno extremo que produce impactos negativos sobre el medio y la sociedad, que es el resultado de multiplicar el valor de la peligrosidad por los daños causados (medido en unidades monetarias). Dauphine (2001) define el riesgo como el producto de la peligrosidad y la vulnerabilidad que se da en un territorio. En contraste con estas definiciones, desde la aproximación social y de la percepción se han propuesto otras que tienen en cuenta el carácter humano subyacente en los procesos de riesgos. Calvo García-Tornel (2001) señala que la medida del riesgo es siempre humana. Por su parte, Beck (2002) va más allá a la hora de señalar el carácter social de los riesgos y defiende que el riesgo es el enfoque moderno de la previsión de las consecuencias futuras de la acción humana. En esta misma lí- 
nea, Giddens (2003) abunda en que los riesgos son creaciones de nuestro conocimiento creciente sobre el mundo.

Teniendo en consideración lo anterior se puede afirmar que la condición de riesgo de un espacio geográfico muestra las características de comportamientos humanos poco adaptados al entorno natural, por lo que el componente natural de los riesgos naturales juega simplemente un papel explicativo en el desarrollo de un evento de peligro. Desde este punto de vista, hay un elemento clave en el análisis de riesgo: la vulnerabilidad, que alude al grupo social, y las actividades que desarrolla en el territorio, que queda expuesto a un peligro natural. Un sistema altamente vulnerable convierte cualquier acción territorial en una actividad de alto riesgo ante un evento extremo. La vulnerabilidad establece la gradación del riesgo en un territorio, de manera que no se entiende el análisis de riesgo sin el estudio del componente humano. Es imprescindible actuar para reducir la vulnerabilidad con el objeto de poder hacer una planificación acorde al territorio y a la protección de las personas, máxime en un escenario en que la recurrencia de los fenómenos extremos parece aumentar según la modelización del proceso actual de calentamiento global (Grinsted et al., 2012; IPCC 2021). Esto es especialmente importante en el caso de las inundaciones en la región mediterránea (Blöschl et al., 2020), donde el papel del ser humano como agente causal destacado de los procesos de inundación también ha tenido un protagonismo creciente en las últimas décadas (Barredo, 2007).

De los tres elementos integrantes del riesgo, la vulnerabilidad es el que más dificultades de análisis conlleva. Este concepto es, en efecto, compuesto y multidimensional, sujeto a interpretaciones sociales y políticas, por lo que su análisis está en función del enfoque investigador. Calvo García-Tornel (1997) señala que la vulnerabilidad es el grado de eficacia de un grupo social determinado para adecuar su organización frente a aquellos cambios en el medio natural que incorporan riesgo. Por su parte, Brooks et al. (2005) defienden que la vulnerabilidad está representada por un conjunto de variables socioeconómicas, políticas y ambientales que informan de la sensibilidad y la exposición de las poblaciones a las amenazas ambientales, y consideran el riesgo como el nivel de deterioro posible provocado por las contingencias ambientales, medido de la sensibilidad o vulnerabilidad de los sistemas expuestos. Según ello, los factores que determinan el nivel de vulnerabilidad dependen de las características ambientales y sociales, del tipo de riesgo, pero también de factores de desarrollo como la pobreza, el estado sanitario, la desigualdad o los factores políticos, entre otros.

La complejidad de las interacciones que determinan la vulnerabilidad hace necesario considerar conceptos como resiliencia y la capacidad de adaptación. Como señalan Smit y Wandel (2006) los conceptos de adaptación, capacidad de adaptación, vulnerabilidad, resiliencia, exposición y sensibilidad están fuertemente interconectados. El término «adaptación» aplicado a los riesgos naturales puede definirse como la capacidad de los grupos o personas para mejorar y añadir nuevos métodos con los que hacer frente a las condiciones medioambientales en función de su repertorio cultural (O'Brien y Holland, 1992). Las estrategias de adaptación son aspectos clave, ya que son manifestaciones de la capacidad de resiliencia (entendida como la capacidad de que un sistema vuelva a la situación previa 
a recibir un impacto con el menor daño posible) y, por lo tanto, representan la forma de reducir la vulnerabilidad (Smit y Wandel, 2006).

Existe una gran heterogeneidad en las definiciones en torno a los riesgos naturales, en relación con la complejidad y el carácter multidisciplinar de su análisis. En este sentido, es adecuado señalar que esta heterogeneidad será mayor si el objetivo es estudiar riesgos naturales con perspectiva histórica, puesto que el contexto económico, cultural y social es cambiante. Además, las fuentes documentales que permiten estudiar los riesgos naturales en el pasado no son espaciotemporalmente homogéneas. Por consiguiente, el enfoque hermenéutico, esto es, la interpretación de los documentos escritos de cada época, sigue siendo imprescindible para lograr una correcta contemporaneidad de los hechos acaecidos (Glaser y Kahle, 2020).

En la investigación histórica de los riesgos naturales, la climatología y la historia social que trabaja los riesgos ambientales han generado numerosas metodologías de reconstrucciones de catástrofes naturales a lo largo del espacio y para distintas épocas. Así, Prieto y Rojas $(2012,2015)$ desarrollan trabajos sobre cómo los extremos hídricos han influido en algunos procesos sociales en Sudamérica en los últimos siglos. Glaser et al. (2017) realizan lo propio para Centroeuropa, Bradzil et al. (2019) para el norte de Europa, y Pfister (2011) para el oeste. Por su parte, Nash et al. (2019) profundizan en la relación sociedad-riesgo natural en el sur de África, Barriendos y Rodrigo (2006) para la península ibérica y Endfield (2007) para el México colonial, por destacar únicamente algunas regiones. Por otra parte, algunos trabajos han explorado más en la posibilidad de establecer metodologías cuantitativas a través del análisis de contexto (Gil-Guirado et al., 2016, 2019; Glaser y Khale, 2020; Prieto y Herrera, 2009) obteniendo óptimos resultados para ámbitos espaciales con una historia y cultura común. Alberola Romá ha aportado una valiosa aproximación al análisis de extremos atmosféricos en época moderna del territorio valenciano a partir de los supuestos de la historia social (Alberola Romá, 1996, 1999, 2010a y b). Este mismo enfoque es el que ha aplicado García Torres $(2017,2018)$ al estudio de peligros biológicos. Sin embargo, todos estos trabajos coinciden en señalar que sin una correcta interpretación hermenéutica de la documentación histórica los resultados obtenidos quedan fuera de contexto (Glaser et al., 2010) y, en consecuencia, no es posible proceder a la verdadera comparación de resultados pasados con los sucesos de la actualidad (Alberola, 2014). A este respecto, los principales problemas metodológicos en estudios de riesgos históricos hacen referencia al hecho de que la heterogeneidad de la documentación existente dificulta establecer metodologías unificadas (Nash et al., 2019). Por otro lado, las divergencias culturales, religiosas y las diferencias socioeconómicas dificultan también la comparación entre espacios geográficos y épocas. No obstante, a pesar de que el estudio de los riesgos naturales históricos entraña dificultades metodológicas y vacíos epistemológicos, en los últimos años se ha producido cierta unificación de procedimientos. Esta homogeneización ha tenido lugar en torno a la escuela de climatología histórica de la que forman parte los autores anteriores y que, de una manera consciente o inconsciente, ha supuesto la estandarización consensuada de enfoques epistemológicos con el objetivo común de aprender de los desastres naturales pasados, con independencia de la finalidad cuantitativa o cualitativa perseguida en un estudio. 
Este trabajo realiza un análisis hermenéutico de la información histórica relativa a las tres mayores inundaciones que afectaron a la ciudad de Murcia (sudeste peninsular) en los últimos siglos: la riada de San Calixto en 1651, la riada de Nuestra Señora de los Reyes de 1733 y la riada de Santa Teresa en 1879. Estas riadas representan la mayor catástrofe natural originada por una inundación, en cada uno de los siglos analizados, en la ciudad de Murcia. El análisis de la documentación histórica evidencia numerosas eventualidades y especificidades que ayudaron o dificultaron la gestión de estos desastres (Gil-Guirado, 2017). Se ha llevado a cabo una reconstrucción cartográfica del área inundable de la ciudad de Murcia gracias a la documentación disponible de principios y finales del siglo xIX. El objetivo de dicha reconstrucción ha sido el análisis de los cambios en el propio curso del río Segura a su paso por la ciudad de Murcia y de las infraestructuras de defensa frente a inundaciones para valorar su contribución frente al impacto de este peligro natural.

De esta manera, la combinación del análisis hermenéutico y el empleo de herramientas de tratamiento informático en el análisis de la documentación cartográfica ha permitido determinar la realidad espacial, social e histórica de las inundaciones en Murcia y valorar si los procesos de adaptación han conducido a una mayor o menor vulnerabilidad y resiliencia frente al riesgo de inundación a lo largo del tiempo (Messerli et al., 2000).

\section{Fuentes y métodos de análisis}

Las inundaciones analizadas en este trabajo se consideran desastres extraordinarios merced al gran impacto social, económico y a las víctimas humanas causadas. Para la elaboración del presente estudio fue necesario diferenciar entre dos tipos de fuentes de datos: a) históricas y $b$ ) actuales.

Las fuentes históricas suponen el grueso de las fuentes empleadas en este trabajo. Por un lado, para el análisis hermenéutico de la riada de 14 octubre 1651 (riada de San Calixto), la riada de 6 septiembre de 1733 (riada de Nuestra Señora de los Reyes) y la riada de 14 de octubre de 1879 (riada de Santa Teresa), las fuentes documentales utilizadas son de carácter primario y de escala de trabajo municipal. A este respecto, el grueso documental corresponde a las Actas Capitulares Municipales (ACM). Las ACM eran documentos municipales de carácter interno donde se recogían textualmente todas las deliberaciones de los concejales y alcaldes («caballeros capitulares») que, reunidos en pleno de forma regular (reuniones del cabildo municipal), trataban todos los asuntos que tenían que ver con la gestión del municipio. Este tipo de documentos suponen la mejor aproximación para observar vicisitudes climáticas de manera directa (Pérez Picazo et al., 1980), esto es, como testimonios registrados que permiten tener un conocimiento muy aproximado de lo ocurrido en un evento destacado del pasado. En ellos, la información extraíble se centra en la influencia sobre la población de los agentes atmosféricos y el devenir del clima. De este modo, los eventos meteorológicos extremos eran siempre tratados de forma exhaustiva (Gil-Guirado, 2017).

La segunda fuente documental trabajada en este primer grupo han sido los periódicos contemporáneos a la catástrofe. Las hemerotecas han sido ampliamente utilizadas para 
la reconstrucción de inundaciones históricas (Rashid, 2011; Gil-Guirado et al., 2016; Barriendos et al., 2019). En este trabajo únicamente se pudo manejar esta fuente para la caracterización de la inundación de 1879.

Adicionalmente se consiguió información de otros documentos de archivo, libros editados tras un evento extraordinario, informes periciales y crónicas, que suponen la tercera fuente de documentación histórica utilizada. Toda la documentación anterior está disponible en el Archivo Municipal de Murcia (AMM) y en el Archivo Histórico Provincial de Murcia (AHPM).

Por otro lado, el análisis cartográfico histórico se ha nutrido fundamentalmente de los mapas realizados por el ejército español durante la guerra de Independencia española (1808-1814). Esta cartografía ofrece un elevado nivel de detalle para la época y está disponible en el portal online del MECD (2020). Para alcanzar una visión espacial completa, se ha consultado material cartográfico histórico en el portal online de la Biblioteca Digital Hispánica (2020) y otra cartografía contenida en legajos e informes disponibles del AMM. Para el manejo de esta documentación con información espacial se tuvo que digitalizar y georreferenciar previamente. Destacan, en especial, dos mapas entre todos los consultados. El primero, de 1809, titulado Plano que manifiesta la Huerta de Murcia, preparada para inundarla caso de ser amenazada de Invasión la Capital por los Enemigos, de Pablo del Villar, disponible en el MECD (2020). Esta cartografía ha servido para delimitar el área de estudio sobre la región histórica de la Huerta de Murcia, pues en ella vienen recogidas las principales zonas urbanas de la época. No obstante, conviene indicar que, a pesar del gran nivel de detalle del mapa, es necesario tener en cuenta que se pueden producir notables desajustes con la realidad de la época. El segundo, con título Croquis de la buerta de Murcia; Partidos En que está Dividida: superficie ocupada por la inundación de 15 de Octubre de 1879, altura que han alcanzado las aguas en la avenida y estadística aproximada de las pérdidas sufridas, de Juan Belando, disponible en la Biblioteca Digital Hispánica (2020), proporciona una idea más aproximada del impacto espacial de dicho evento.

De la combinación de los mapas anteriores mediante el manejo de un sistema de información geográfica (SIG) se han podido trazar los cambios producidos en el curso del río Segura en las inmediaciones de la ciudad de Murcia entre 1809 y la actualidad. La cartografía ha sido elaborada con el software de libre uso QGIS (QGIS Development Team, 2016).

\section{Ámbito de estudio. Aspectos geográficos e históricos}

La ciudad de Murcia, fundada por iniciativa de Abderramán II en el año 825 d. C. en la parte cóncava de un meandro próximo a la estrangulación en la margen izquierda del río Segura, nació con la intención de establecer un punto habitable y estable con el que poder controlar el área y explotar las fértiles tierras del valle, al resguardo de la mayor amenaza de la zona: las inundaciones. Para ello, fue necesario, por un lado, un enorme esfuerzo hu- 
mano con el que regularizar la mutabilidad espacial del cauce que de manera natural abandona y crea nuevos meandros (Lillo Carpio, 2000) y, por otro, controlar la irregularidad temporal de los caudales del río.

Los rasgos climáticos del área de estudio están caracterizados por unas precipitaciones exiguas (ligeramente inferiores a los $300 \mathrm{~mm}$ ) con ocho meses de escasas precipitaciones, una acusada sequía estival y una fuerte irregularidad inter e intraanual. Se unen a ello unas temperaturas medias anuales elevadas (superiores a los $18^{\circ} \mathrm{C}$ ), con veranos muy calurosos e inviernos suaves. Estas condiciones aumentan el estrés hídrico tanto para las poblaciones humanas como para las comunidades bióticas, puesto que el período anual de mayor demanda de agua corresponde a los de menor aportación natural de los ríos y de menor precipitación. Son especialmente críticos, en este sentido, los meses de junio, julio y agosto (Gil-Guirado y Pérez-Morales, 2019). Este hecho, junto con el calendario agrícola local de los cultivos practicados, va a orientar a la economía del valle, predominantemente agraria hasta hace pocas décadas, alrededor de este sistema natural y la variabilidad climática e hidrológica que pueda tener.

El actual término municipal de Murcia ocupa $885,5 \mathrm{~km}^{2}$, una extensión importante que conviene matizar, puesto que históricamente han cohabitado dos áreas diferenciadas. Por un lado, la propia ciudad, su huerta y poblaciones circundantes y, por otro, el campo de Murcia, representado por los núcleos poblacionales al sur de la urbe y que por lo general tiene un comportamiento económico distinto. En este último, el cultivo en secano siempre ha predominado sobre el regadío por la ausencia de un cauce con caudales continuos.

El carácter agrario de la ciudad de Murcia y de su área próxima ha sido, como en todos los poblamientos antiguos, el factor de localización de las actividades, lo que, en este caso, y dadas las condiciones climáticas, se ha traducido en un determinismo hídrico por encima de cualquier otra demanda. Esta situación condicionará que en la ciudad pasen a un plano secundario las necesidades defensivas propias de un territorio histórico de frontera entre los antiguos reinos cristianos y musulmanes. De esta manera, el papel del recinto amurallado de la ciudad frente a las inundaciones, aunque fuese concebido como un sistema de defensa ante eventuales ataques militares, ha sido siempre el más importante (figura 1) (Roselló Verger y Cano García, 1975). Consecuentemente, en la ciudad de Murcia tampoco se ha primado el control efectivo del espacio circundante desde una localización elevada de carácter defensivo.

La muralla medieval de la ciudad de Murcia tiene su origen en el período de dominio musulmán; fue construida entre los siglos xi y xII. Ya en el siglo xvir el humanista y erudito murciano Francisco Cáscales señaló que la muralla de Murcia había sido levantada para defensa de ataques enemigos, protección de riadas y epidemias (Cascales, 1621). Por su parte, García Antón (1993) destaca el papel determinante que ha jugado la muralla de Murcia para proteger a la ciudad de las inundaciones del río Segura. No obstante, fueron Torres Fontes y Calvo García-Tornel (1975) los autores que más incidieron en la función que históricamente desempeñó la muralla como defensa frente a las inundaciones.

El cambio funcional reciente experimentado en la ciudad ha propiciado que la Huerta haya pasado de ser el cinturón verde, fuente de producción de los productos hortícolas 
Figura 1

Plano de la ciudad de Murcia (1810)

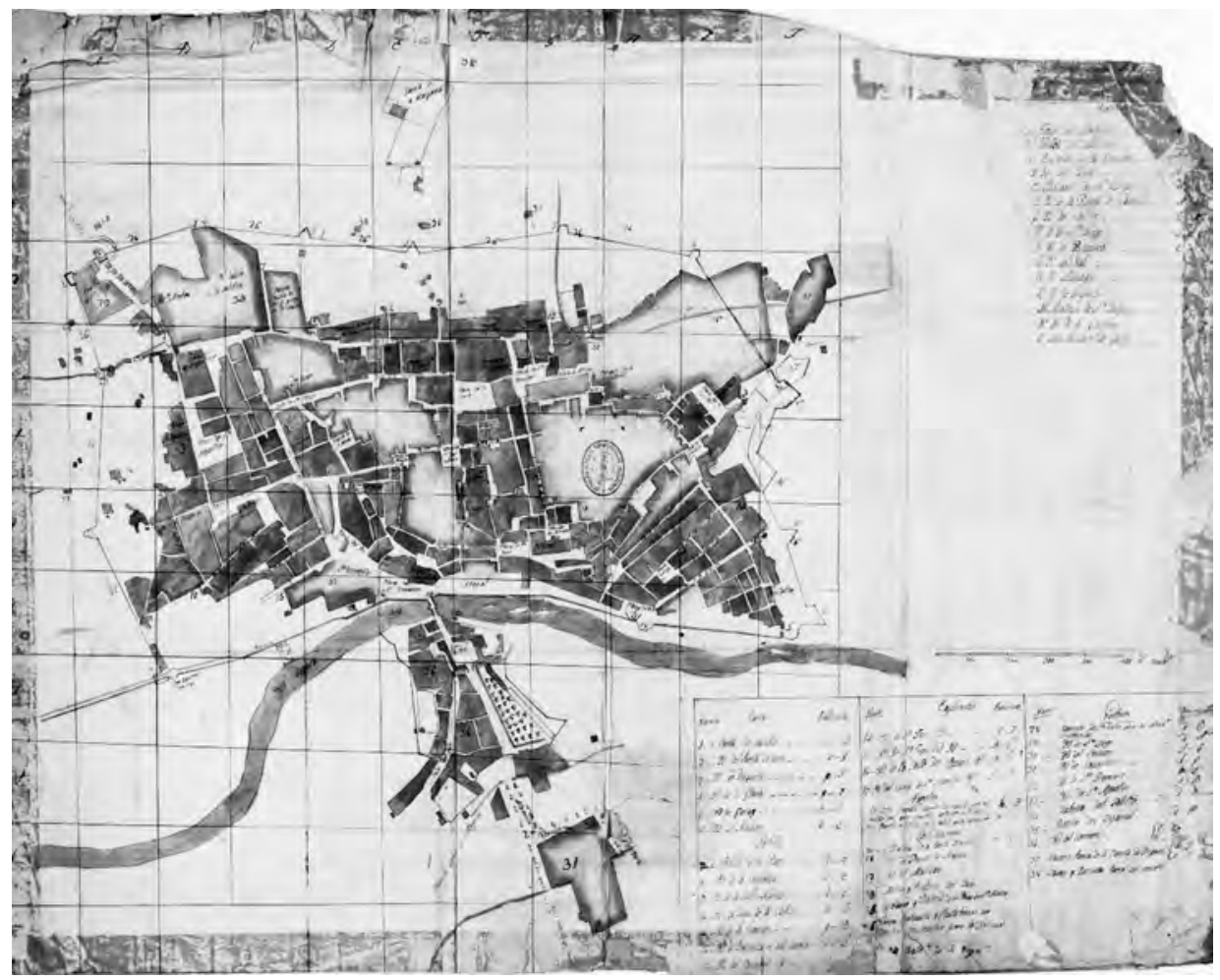

Nota: En el plano se aprecia claramente la muralla. En él aparece la relación de las puertas, puentes, fortificaciones y edificios indicados mediante clave alfanumérica.

Fuente: MECD, 2020.

consumidos en la ciudad, a una zona de reserva de suelo urbano, modificando el esquema básico de organización de la huerta tradicional. Un espacio caracterizado por unos condicionantes ambientales que han generado un paisaje cultural, abigarrado, homogéneo en su conjunto, diferenciado del entorno por el uso del regadío. Territorio que presenta un continuo histórico y espacial, que va más allá de las divisiones político-administrativas, puesto que, aunque la mayor parte de su extensión se engloba dentro del municipio de Murcia, el territorio histórico de la Huerta de Murcia está presente en sectores de otros cinco municipios (Molina de Segura, Alcantarilla, Santomera y Beniel, en la provincia de Murcia, y Orihuela, en vecina provincia de Alicante) (figura 2).

Se advierte cómo el río Segura, la huerta y la ciudad de Murcia han sufrido una evolución en la historia reciente que ha ido reduciendo los usos agrarios tradicionales para dar legitimidad al actual desempeño de las funciones del área metropolitana, con gran parte del es- 
Figura 2

\section{Área de estudio}

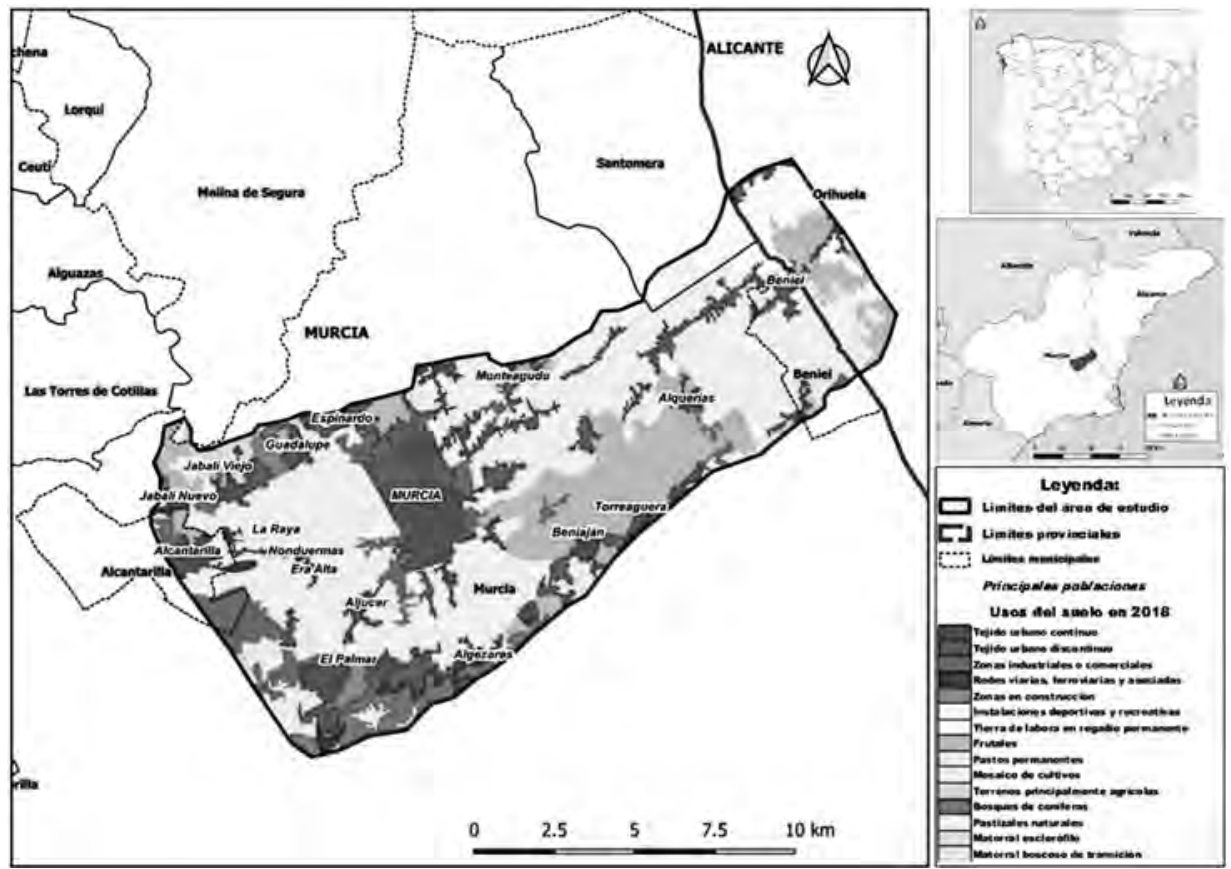

Notas: El perímetro del área de estudio se corresponde con la región histórica de la Huerta de Murcia. La delimitación de esta área se ha realizado según el mapa de 1809 titulado Plano que manifiesta la Huerta de Murcia, preparada para inundarla caso de ser amenazada de invasión la capital por los enemigos, de Pablo del Villar, disponible en el MECD (2020).

pacio actual terciarizado, a excepción de pequeños vestigios de cultivos de regadío (figura 2). La organización de este espacio se dispone en la Depresión Prelitoral Murciana, vertebrada por el río Segura y la confluencia del río Guadalentín, en este por su margen derecha. En ambos casos, la llanura aluvial está conformada por terrenos de escasas pendientes y fértiles suelos aluviales en los que se han asentado las actividades agrícolas. El río Segura se adentra en el área con dirección NW-SE y aumenta la anchura de su valle a medida que se acerca a las inmediaciones de la ciudad de Murcia. El Guadalentín, por su parte, confluye de manera natural con el río Segura, formando un gran cono aluvial, continuación del fondo de valle, que discurre sobre la falla de Alhama con dirección SW-NE. Sin embargo, a partir del año 1747 entra en funcionamiento el canal del Reguerón, cuya función principal será derivar el río Guadalentín para que no confluya con el río Segura aguas arriba de la ciudad. Los flancos de estos valles lo establecen relieves de escasa altitud de la cordillera Subbética.

Conviene destacar las características de la confluencia natural del Guadalentín con el Segura, puesto que el riesgo de inundación implícito ha determinado de forma secular las 
directrices de ordenación de este espacio. Esta unión se produce aguas arriba de la ciudad, en el lugar denominado Paso de los Carros, a pocos kilómetros de la localidad de Sangonera. La zona conforma un gran abanico aluvial (de unos $30 \mathrm{~km}^{2}$ ) en el que la topografía y régimen del río incrementan el riesgo de divergencia del cauce. Esto constituye un factor determinante en la exposición de este territorio ante las inundaciones. En efecto, ha motivado que a lo largo de la historia de la urbe las estrategias y planificación seguidas para mitigar esta situación girasen en torno al control de la peligrosidad torrencial del Guadalentín (Calvo García-Tornel, 1969).

Esta es la relación dual que da carácter geográfico al área de estudio, por sus intentos de dominio y control del agua, para disponer de caudales con los que escapar de sequías y, al mismo tiempo, las acciones para no verse afectada por la impetuosidad de las inundaciones. Estos factores, al margen del contexto económico y político nacional e internacional, han determinado las posibilidades de crecimiento de la ciudad debido al lastre que han supuesto las importantes catástrofes ocurridas a lo largo del tiempo y que han sido, paralelamente, un acicate por la necesidad de su mitigación. Así, a períodos históricos de desarrollo en la zona, seguidos de alzas poblacionales, se han seguido períodos de depresión o estancamiento, ante la imposibilidad de mantener estas nuevas demandas con la tecnología de producción agraria y control estructural del agua del momento (Pérez Picazo et al., 1980). Los orígenes de este proceso se remontan a la implantación del sistema de riego en el siglo xi, que ha pervivido, prácticamente intacto, hasta las décadas finales del siglo xx (Ros Sempere y García Martín, 2012).

\section{Tres inundaciones catastróficas en la ciudad de Murcia: San Calixto (s. XVII), Nuestra Señora de los Reyes (s. XVIII) y Santa Teresa (s. XIx)}

La inundación de San Calixto del 14 de octubre de 1651 en Murcia fue la más desastrosa del siglo xvi y, junto con la de Santa Teresa en 1879, puede considerarse la riada que más perjuicio causó en la ciudad en época moderna de las que se tenga constancia. Originada tras unas intensas lluvias otoñales, el súbito desbordamiento del río Segura cogió a la población desprevenida por el momento del día en que se produjo (durante la madrugada), aspecto que, por otro lado, era un rasgo repetido en las inundaciones importantes de ese período histórico. Los daños consignados evidencian que la crecida provino tanto del Segura como del Guadalentín, por lo que el episodio de precipitación debió de ser generalizado en toda la cuenca del río Segura o, al menos, en su sector W y NW. Durante las primeras horas, la gestión de la catástrofe se centró en asegurar, con los medios disponibles, las defensas de la ciudad para defenderse ante una nueva crecida, pero la falta de un fondo de ayuda para estos frecuentes casos comprometió el socorro inmediato. ${ }^{4}$ cia, AMM).

4. Actas Capitulares de la ciudad de Murcia de 15, 18, 19 y 20 de octubre de 1651. Fuente original manuscrita (Mur- 
Durante tres días las aguas inundaron las calles de la ciudad y hubo que esperar hasta el cuarto para poder celebrar una reunión del cabildo municipal en la que se evaluara la situación y valorara la magnitud de la catástrofe. En la junta extraordinaria del cabildo municipal de 18 de octubre, los caballeros capitulares hicieron una valoración preliminar de daños y describieron un panorama desolador. ${ }^{5}$ El jueves 19 de octubre, tras un reconocimiento algo más exhaustivo, se evaluó la magnitud del desastre: casas derribadas, ganado muerto, defensas destruidas, red de acequias imposibilitada, comunicaciones cortadas y una funesta relación de centenares de víctimas fatales. Tal fue el estado de ruina de la ciudad que se produjo un éxodo de supervivientes hacia las partes más altas del valle del Segura. La situación de quiebra financiera que arrastraba la ciudad incrementó la vulnerabilidad social por la falta de dinero para proceder a los reparos; finalmente se acordó acudir al socorro del rey para que eximiera de impuestos, mandase peritos para reconocer los daños y destinase fondos de ayuda a damnificados.

A los daños en infraestructuras se siguieron de forma inmediata los problemas de abastecimiento y la consiguiente subida del precio de los alimentos. Se inició una cadena de solidaridad, como era costumbre en casos de graves inundaciones en la ciudad. El primero en ofrecer su ayuda fue el vecino municipio de Mula, a pesar de haber sufrido también importantes daños. Una de las medidas del rey fue crear un impuesto entre todas las localidades del Reino de Murcia, en función de su tamaño poblacional, para impulsar así la reconstrucción de su capital. Por otro lado, y por mandato municipal, todos los vecinos sin distinción aparente de clase tuvieron que ayudar en las tareas de reparación de infraestructuras de comunicación y de defensa frente a inundaciones. ${ }^{6}$

Un mes después de la inundación, las calles aún seguían intransitables, anegadas y llenas de barro depositado por las aguas de crecida que afectaron gravemente al comercio. Además, algunos edificios se derrumbaron por la acumulación de humedad. Más de dos meses después la situación seguía siendo caótica: el sistema de riego continuaba colapsado, el río pasó a ocupar nuevos espacios en el llano de inundación, por lo que los molinos no podían moler granos, una parte de la población continuaba el éxodo hacia otras localidades del valle del Segura, escaseaban los alimentos y se incrementó su precio, entre otras fatalidades. En este contexto, los mismos gestores municipales señalaban indirectamente que el estado de vulnerabilidad previo al evento fue en parte responsable de la intensa penuria que provocó este desastre.

Cuatro meses después de estos trágicos acontecimientos, la ciudad parecía haber superado lo peor, por lo que se decide hacer una misa de acción de gracias. ${ }^{7}$ No obstante, durante muchos meses más seguirían los arreglos de las infraestructuras.

En cualquier caso, teniendo en cuenta los medios disponibles, los sistemas de prevención, control y evaluación de la amenaza estaban bastante desarrollados en Murcia; sin embargo, el problema principal que traducen las fuentes consultadas era el contexto sociopolítico y económico.

5. Actas Capitulares de la ciudad de Murcia de 18 de octubre de 1651. Fuente original manuscrita (Murcia, AMM).

6. Actas Capitulares de la ciudad de Murcia de 19 de octubre de 1651. Fuente original manuscrita (Murcia, AMM).

7. Actas Capitulares de la ciudad de Murcia de 10 de febrero de 1652. Fuente original manuscrita (Murcia, AMM). 
Respecto a la peligrosidad o características físicas de la onda de crecida, son escasas las informaciones donde se señale la explicación físico-ambiental de la riada. Entre las infraestructuras dañadas, el sistema de regadío y, sobre todo, las obras de protección contra avenidas fueron las más afectadas. Consecuentemente, las alteraciones económicas a la agricultura y los problemas de abastecimiento de agua de riego fueron muy importantes. ${ }^{8}$ Mención aparte merecen las víctimas mortales y heridos. Sin embargo, pese a la magnitud del desastre, no se dio la importancia suficiente a este asunto. La poca relevancia dada en este siglo a las víctimas mortales pudiera estar relacionada con las altas tasas de mortalidad de la época y la baja esperanza de vida, cuestiones que hacían que una vida no tuviese la consideración que se otorga en la actualidad tras un evento de estas características.

La riada de San Calixto en 1651 establece un importante precedente en la gestión de un riesgo natural en el área de estudio, pues se realizaron constantes peticiones municipales a la Corona para ayudas y exención de impuestos y, además, se implicó de manera activa a todos los agentes sociales afectados. Resultaba notable, sin embargo, que tanto los nobles de alto rango como los caballeros enviaban a súbditos y vasallos a trabajar por ellos en las tareas de recuperación tras el desastre. ${ }^{9}$ El cabildo eclesiástico inició una batalla abierta contra los caballeros hidalgos y el propio cabildo municipal, con el pueblo como mero agente espectador al cual adoctrinar en su propio beneficio. Durante la misa de acción de gracias realizada por haber superado la ciudad la inundación, el párroco aprovechó para reprochar al cabildo municipal que los religiosos no hubieran tenido la posibilidad de mandar a alguien a trabajar en su nombre, como sí pudieron hacer los nobles. Y todo ello mientras el párroco se sumaba al sufrimiento del pueblo llano. ${ }^{10}$ La realidad parece así demostrar que las élites en todo momento histórico se han apropiado de las respuestas populares legítimas ante las injusticias, deformando la intención inicial e introduciendo nuevos actores en función de su interés particular. Por otro lado, se hace evidente que la generalización de los procesos de riesgo no es una consecuencia específica de la modernidad, tal como señala Beck (2002). En cuanto a los mandatarios, en ocasiones la propia documentación histórica muestra cómo las autoridades culpan a la propia población rural, a industriales, ganaderos e incluso a algunos concejales por las malas prácticas respecto al correcto mantenimiento de la red de riego y sistema de defensa contra inundaciones. También se señala a los especuladores de los problemas alimentarios, al encarecer intencionadamente los productos.

La inundación de Nuestra Señora de los Reyes, ocurrida el 6 de septiembre del año 1733 en Murcia, fue seguramente la más catastrófica del siglo xviII. Al igual que la situación descrita para el evento acaecido en el siglo anterior, unas defensas frente a inundaciones en deplorable estado de conservación y la incapacidad de solventar el problema de forma eficaz y diligente estarían en el origen de la magnitud del desastre vivido. Basta señalar

8. Actas Capitulares de la ciudad de Murcia de 18, 19 y 20 de octubre de 1651. Fuente original manuscrita (Murcia, AMM).

9. Actas Capitulares de la ciudad de Murcia de 11 de noviembre de 1651. Fuente original manuscrita (Murcia, AMM).

10. Actas Capitulares de la ciudad de Murcia de 12 de febrero de 1652. Fuente original manuscrita (Murcia, AMM). 
que menos de un mes antes de la inundación se produjeron daños en el sistema de riego, pero la excesiva burocracia y la falta de dinero dificultó su arreglo inmediato al ser conscientes de que se aproximaba la temporada de lluvias. ${ }^{11}$

En dicha jornada de septiembre, un intenso, continuado y generalizado episodio de lluvias comenzó a hacer crecer las aguas del río Segura. El desbordamiento, a pesar de los intentos, no se pudo frenar. Al contrario que en la crecida de San Calixto, en donde los picos de avenida provenían tanto del río Segura como del Guadalentín, ahora la fuerza de la crecida provino principalmente del segundo, lo que supondría un grado de peligrosidad menor con caudales punta menos extremos. La estrategia de mitigación de daños fue bastante acertada en los primeros momentos de la emergencia, en los que se establecieron grupos de respuesta rápida para reparar los desperfectos en los sistemas de defensa y evitar así mayores daños. ${ }^{12}$ Pese a todo, los daños fueron cuantiosos, principalmente para la agricultura, los sistemas de riego y defensa de la ciudad y la Huerta, así como para las comunicaciones. Se inundaron multitud de viviendas y barrios enteros. La mala calidad de las construcciones en la huerta motivó que muchas barracas fueran destruidas y arrastradas por las aguas; además, se produjeron numerosas víctimas mortales, aunque en cantidad menor que en la riada del siglo anterior analizada. Nuevamente, la falta de un fondo estable de previsión ante estos frecuentes desastres dificultó la gestión inmediata y dejó en la ruina al erario local. Los problemas de abastecimiento ante la pérdida de cosechas, arrastre de producciones, interrupción de las comunicaciones e imposibilidad de moler los molinos fueron inmediatos, lo que provocó carestía, hambre y fuertes subidas en los precios del pan. ${ }^{13}$ De forma general, las medidas urgentes siguieron el mismo protocolo que durante el siglo xviI.

La diferencia importante entre el impacto de este evento y el de 1651 queda reflejada por el hecho de que mientras que en este último episodio hubo que esperar cuatro meses para hacer la misa de acción de gracias por haber librado Dios a la ciudad de la inundación, en esta ocasión la celebración eclesiástica se llevó a cabo tan solo seis días después, y en ella se informó de que las aguas en su mayor parte se habían retirado y los conventos y que algunas calles eran ya transitables. ${ }^{14}$

Al igual que lo ocurrido tras la inundación analizada del siglo xvis, se remitió un informe de daños al rey con un relato exagerado de los hechos.$^{15}$ Dos semanas tras la inundación se comienzan a tomar medidas de adaptación para prevenir nuevos daños, que, dentro del comportamiento habitual de la época, se centraron en recortar meandros y en reasegurar y mejorar el sistema de defensa y riego. La falta de medios obligó a hacer un reparto de gastos entre los propietarios de tierras para asumir los costes de la reconstrucción. Ante la negación o demora de algunos terratenientes a costear estas obras, se los amena-

11. Actas Capitulares de la ciudad de Murcia de 6 de febrero y 11 de agosto de 1733 . Fuente original manuscrita (Murcia, AMM).

12. Actas Capitulares de la ciudad de Murcia de 6 de septiembre de 1733. Fuente original manuscrita (Murcia, AMM).

13. Actas Capitulares de la ciudad de Murcia de 10 de septiembre de 1733. Fuente original manuscrita (Murcia, AMM).

14. Actas Capitulares de la ciudad de Murcia de 12 de septiembre de 1733. Fuente original manuscrita (Murcia, AMM).

15. Actas Capitulares de la ciudad de Murcia de 10 de septiembre de 1733. Fuente original manuscrita (Murcia, AMM). 
zó con excluirlos de las acciones de mejora. A pesar de todo, veinte días después, aún la huerta y la ciudad seguían sin agua para riego y consumo doméstico, tanto por la rotura de infraestructuras, como, especialmente, por la acumulación de sedimentos que cegaba las conducciones. ${ }^{16}$

La dependencia de Murcia de las ayudas y créditos, así como la falta de previsión, generaron graves afecciones económicas. Por su parte, la menor virulencia de la inundación quedaba manifiesta por la menor información sobre víctimas mortales y heridos en comparación con la ocurrida un siglo antes. En este episodio, la documentación muestra un hecho significativo: la causa principal de la avenida fue la crecida fluvial, esto es, la naturaleza era la responsable del desastre. No obstante, hubo un incremento de las críticas a la acción humana como responsable del impacto de la inundación. A este respecto, se culpó a los técnicos encargados de revisar las infraestructuras y al mal estado de estas.

La inundación de Santa Teresa de 1879 ha pasado a los anales de la historia como la más catastrófica de la que se tenga constancia en Murcia. Los daños materiales fueron incalculables y las víctimas se contaron por centenares. La respuesta ante el desastre padecido por el pueblo murciano conllevó, en esta ocasión, la puesta en marcha de un movimiento solidario a escala mundial sin precedentes hasta esa fecha (Botrel, 2019). La magnitud del desastre tuvo reflejo en crónicas y documentos editados en los días y semanas siguientes a la inundación (Carles, 1879; Paris-Murcie, 1879) y ha sido objeto de diversos estudios desde las disciplinas histórica y geográfica (Torres Fontes, Perea y Gómez, 1962; Gil Olcina, 1968; López Bermúdez et al., 1981). Se han habilitado, asimismo, portales web con información sobre la riada de Santa Teresa, a cargo de organismos públicos (Confederación Hidrográfica del Segura) ${ }^{17}$ e instituciones, empresas de comunicación (Región de Murcia digital, ${ }^{18}$ diario La Verdad $)^{19}$ que ofrecen abundantes recursos documentales, escritos y gráficos, de gran interés para la comprensión de la importancia histórica de este episodio.

La crecida tuvo su origen en un intenso episodio lluvioso de más de dos días de duración generalizado en toda la cuenca hidrográfica. Las puntas de crecida que llegaron a la ciudad provenían tanto del Guadalentín como del resto de los ríos de la margen derecha (Mula, Quipar, Argos y Moratalla) y también de la margen izquierda del Segura.

De la gravedad de la inundación de Santa Teresa da cuenta la urgencia y premura ocurrida para gestionar la catástrofe. Así, el cabildo de Murcia celebró cinco días seguidos de sesiones extraordinarias (días 15, 16, 17, 18 y 19 de octubre) para tratar exclusivamente de la gestión de la inmensa crecida. ${ }^{20}$

El día 15 de octubre la ciudad estaba por completo inundada y los diarios de la época se hacían eco del desastre y daban cuenta, ante la imposibilidad de comenzar el socorro,

16. Actas Capitulares de la ciudad de Murcia de 30 de septiembre de 1733. Fuente original manuscrita (Murcia, AMM).

17. Véase https:/www.chsegura.es/es/confederacion/unpocodehistoria/cronologia-de-riadas-en-la-cuenca-del-Segura/.

18. Véase https://www.regmurcia.com/servlet/s.Sl?sit=c,373,m,1096\&r=ReP-15045-DETALLE_REPORTAJESPADRE.

19. Véase https://www.laverdad.es/ababol/arte/riada-santa-teresa-20191019215808-nt.html.

20. Actas Capitulares de la ciudad de Murcia de 15, 16, 17, 18 y 19 de octubre de 1879. Fuente original manuscrita (Murcia, AMM). 
de los primeros movimientos burocráticos de emergencia, como crear la Junta de Socorros (lo que podría considerarse un antecedente de la actual declaración de zona catastrófica) (figura 3). Desde el primer momento, se temía que los daños en la Huerta fueran, posiblemente, mucho más graves que en la ciudad.

\section{Figura 3}

Titular de prensa los días posteriores a la riada de Santa Teresa

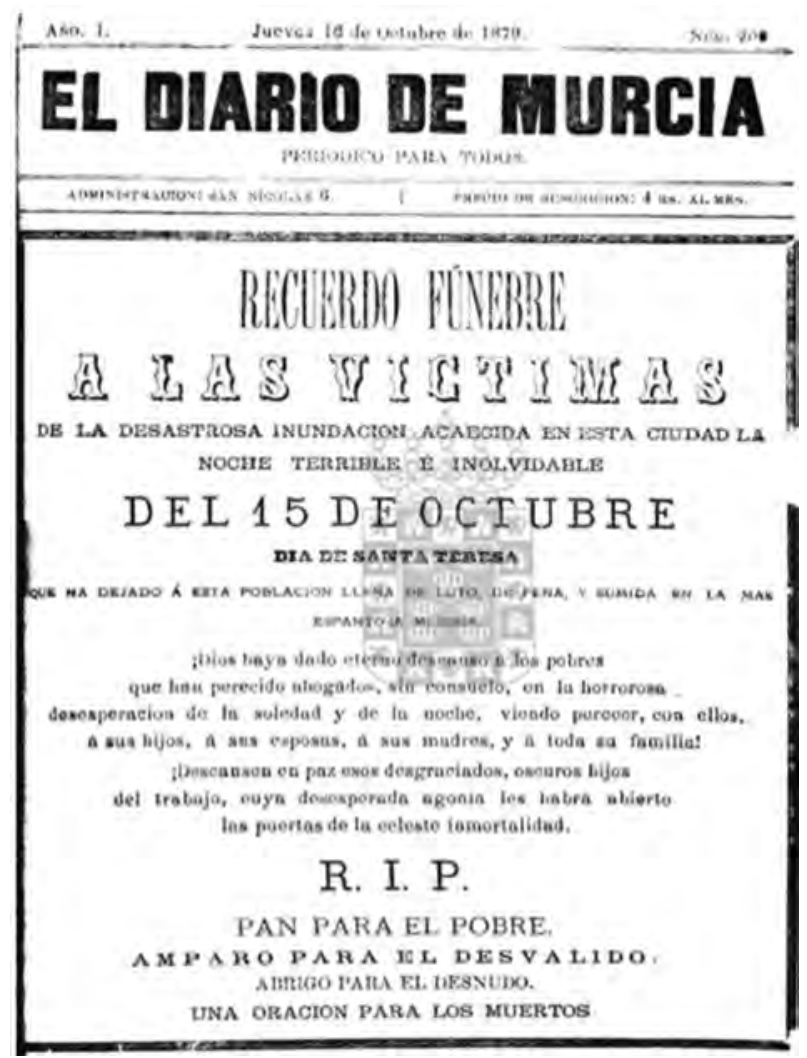

Fuente: Diario de Murcia (16 de octubre de 1879).

Una noticia del día 16 de octubre de El Diario Información lo expresaba así: «10.000 labradores han perdido indudablemente en esta noche tristísima todo cuanto tenían; mañana, enlutados y llorosos, vendrán a nuestras calles a pedirnos una limosna, y es necesario que las autoridades les socorran, que les den pan a los que tengan hambre. Hoy mismo debe saber el Rey, el Gobierno, la Nación entera, que esta desgraciada ciudad ha quedado 
pobre y miserable; hoy debe oírse por toda España la voz de Murcia que pide una limosna para un número inmenso de sus hijos que lo han perdido todo».

Dentro de la ciudad, las áreas próximas a la margen izquierda del río fueron las más afectadas. El barrio de San Benito (en la zona sur de la ciudad) fue el primero en inundarse y el epicentro de la catástrofe, registrando una destrucción prácticamente total. El agua llegó al centro urbano, inundando todo el barrio de San Pedro; también se inundó la cárcel, la catedral, el barrio de San Juan y el de San Andrés. En la Huerta la situación fue peor, con numerosos cadáveres esparcidos por los campos de cultivo inmediatos a la zona urbana. La pedanía de Nonduermas quedó anegada por completo, al igual que las pedanías de Era Alta, Beniaján, Alquerías, Aljucer, Rincón de Seca, La Alboreja, San Benito, El Raal, Urdienza, Puente Tocinos, como más afectadas. ${ }^{21}$ El día 16 de octubre se contabilizaron 113 víctimas fatales, a pesar de no haber podido acceder a las zonas más afectadas. En enero del año siguiente las cifras oficiales de víctimas se elevaban a 148, aunque con los numerosos desaparecidos previsiblemente el número ascendería a 300 tan solo en la capital y la Huerta. En Orihuela, en la vecina provincia de Alicante, se veían cadáveres sobre las aguas del río que provenían de Murcia.

El desastre conmovió a la opinión pública española y extranjera. De este modo, el día 20 de octubre el rey Alfonso XII llegó a Murcia para visitar la zona afectada. La movilización de la caridad internacional, como se ha señalado, no tuvo precedente, sobre todo desde las antiguas colonias españolas y las que aún seguían siéndolo (Cuba, Filipinas y Puerto Rico) y más, si cabe, desde Francia, donde la prensa parisina dio mucha importancia al suceso, hasta el punto de crear un fondo de participación para ayuda a afectados y una lotería para recaudar fondos. También desde el resto de las localidades de la cuenca del Segura y del resto de España la ayuda fue inmediata. El movimiento de solidaridad comenzó tan solo dos días después de la riada. ${ }^{22}$

En cuanto a la valoración económica de los daños, el sensacionalismo de la prensa escrita dificultaba hacerse una idea de magnitud real de los daños de la riada al exagerar sus efectos. La Huerta de Murcia, en su conjunto, con sus más de 20.000 ha quedó sumergida por las aguas y por la gran cantidad de sedimentos que arrastró la corriente, en algunos lugares una vez retiradas las aguas, la altura de los sedimentos acumulados casi llegó a alcanzar los 2 m (figura 4). La destrucción fue casi total y los daños, incalculables.

Hasta el día 22, las autoridades solo se dedicaron al socorro tras el desastre. ${ }^{23}$ A partir de esa fecha comenzaron las labores de reconstrucción del sistema de defensa contra inundaciones y distribución de agua, al tiempo que empezaron a proponerse medidas para evitar que volviera a repetirse el desastre. Se trataba de un conjunto de medidas que, en la mayoría de los casos, pasaban por la realización de obra pública.

En las noticias de los periódicos se reflejaba la nueva conciencia de clase decimonóni$\mathrm{ca}$, al diferenciarse entre jornaleros pobres, propietarios de la tierra y el resto de la socie-

21. Actas Capitulares de la ciudad de Murcia de 18 y 19 de octubre de 1879. Fuente original manuscrita (Murcia, AMM).

22. Noticia de El Diario de Murcia de 18 de octubre de 1879. Fuente original mecanografiada (Murcia, AHPM).

23. Actas Capitulares de la ciudad de Murcia de 22 de octubre de 1879. Fuente original manuscrita (Murcia, AMM). 


\section{Figura 4}

Croquis de la huerta de Murcia; Partidos En que está Dividida: superficie ocupada por la inundación de 15 de octubre de 1879, Altura Que Han Alcanzado las aguas en la avenida y estadística aproximada de las Pérdidas sufridas, por D. Juan Belando

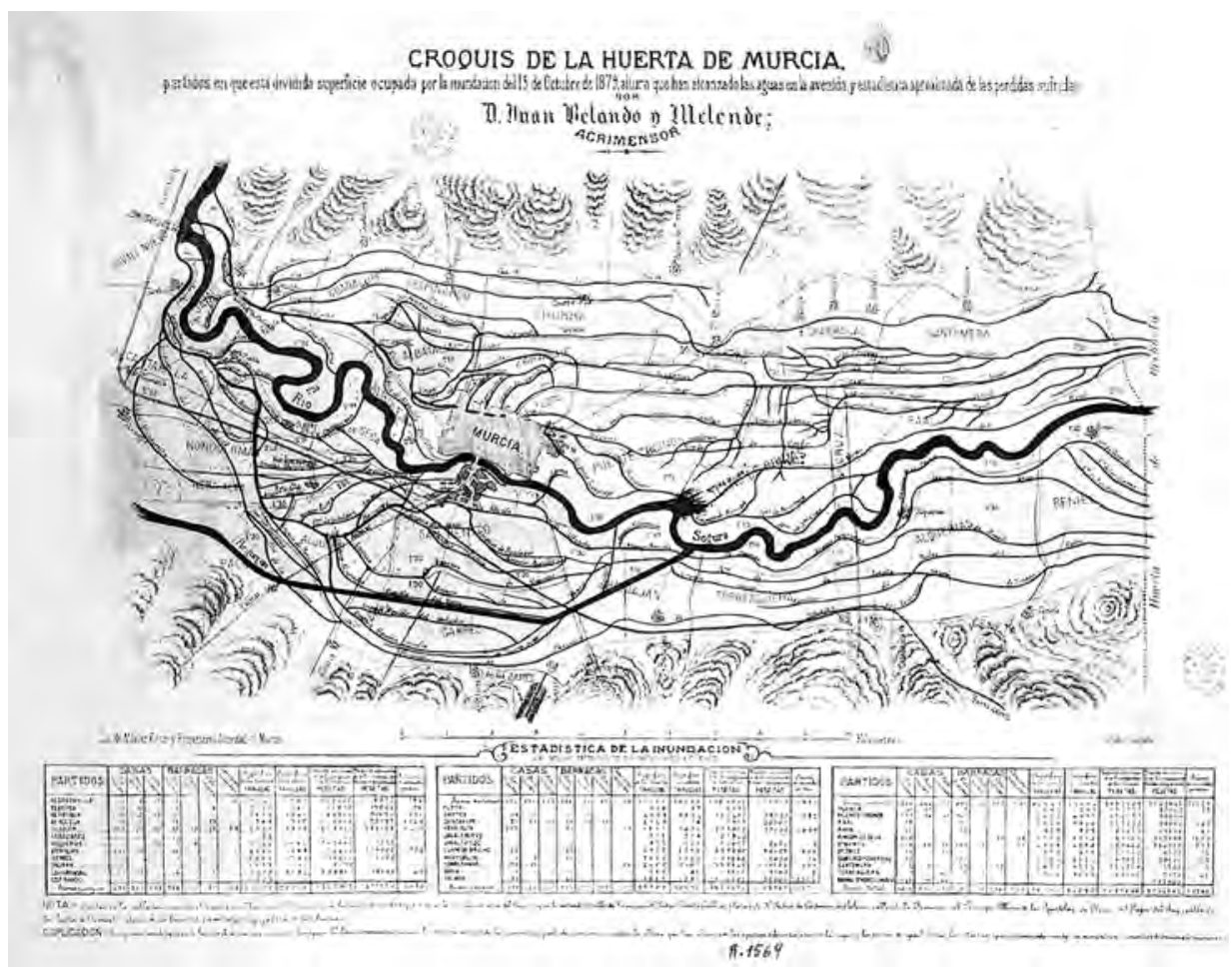

Fuente: Biblioteca Digital Hispánica (2020).

dad de entonces. ${ }^{24}$ La mejora de las libertades individuales y políticas, junto con una relativa libertad de prensa durante el reinado de Alfonso XII, evidencian una mayor conciencia crítica de lo ocurrido que apunta directamente a algunas prácticas sociales como responsables de los estragos de la inundación. No obstante, el corporativismo y uso político de los medios de comunicación se dejaron sentir con ocasión de la inundación. A este respecto, el día 16 de octubre de 1879 el Diario de Murcia $^{25}$ ayudaba con su nota de portada al poder político y a las fuerzas de seguridad: «[...] ayer vimos desparramados por esta huerta a todos los concejales, a toda la guardia civil, a todos los bomberos, cuerpo de or-

24. Noticias de El Diario de Murcia de 25 y 28 de octubre de 1879. Fuente original mecanografiada (Murcia, AHPM).

25. Noticias de El Diario de Murcia de 16 de octubre de 1879. Fuente original mecanografiada (Murcia, AHPM). 
den público, y cientos de personas que seguían prestando socorros a los que los necesitaban». Y añadía que en la génesis de la inundación subyacía una cuestión divina: «[...] parece que Dios mira con cólera a esta ciudad». El día 19 se confirma este posicionamiento político: «Repetimos que en Murcia no ha habido autoridad, ni dependiente de ella que no haya hecho cuanto ha podido». A esto se unió el carácter ultraconservador de algunos sectores de la sociedad que culpaba de lo ocurrido a los vicios y malos hábitos de las clases más desfavorecidas. La noticia de 25 de octubre de 1879 de El Diario de Murcia es el mejor ejemplo en este sentido, además de sintetizar de forma indirecta algunos de los problemas seculares de la población del valle del Segura, como el escaso espíritu reivindicativo, el conformismo y la religiosidad. Esta noticia es un ejemplo de las tensiones sociales acrecentadas por la inundación. El mismo diario se vio obligado a responder a las críticas de sectores más progresistas instalados previsiblemente entre las fracciones cultas de la sociedad murciana, pero que, por miedo a las represalias, realizaban sus consideraciones desde el anonimato.

A partir de diciembre de 1879 comenzaron a ser constantes los problemas en el reparto de los fondos de ayuda y los comentarios sobre que no llegaban todos los fondos donados. La mayor parte de los fondos eran donaciones de particulares que ocultaban una cierta condicionalidad de ayudar a los más necesitados, pero parece que una parte de esas ayudas se destinaron a asistir a los grandes propietarios y personas de clase alta, por lo que se abandonó a los más pobres. Nuevamente, algunos sectores de la prensa local hicieron gala del caciquismo imperante y señalaron que los problemas sociales fueron un importante factor de vulnerabilidad. También se puso de manifiesto que los sectores más conservadores fueron los menos predispuestos a mejorar la adaptación al riesgo y la resiliencia territorial, poniendo trabas a que la reconstrucción fuera en áreas más seguras. ${ }^{26}$ Casi tres meses después de la inundación se hizo una valoración realista de damnificados en la que se destacaba que aún quedaban sin atender con ropa a 9.332 personas en la Huerta, a pesar de haber realizado un reparto a cerca de 20.000 afectados.$^{27}$ No obstante, las noticias sobre el recuento de daños aún eran contradictorias.

En marzo de 1880, se puede declarar ciertamente que la inundación había sido superada o al menos interiorizada por la población. Una vez más, los huertanos se hicieron cargo de que su nueva realidad consistía en ser más pobres y miserables de lo que eran tan solo unos meses antes. A pesar de la magnitud de la catástrofe, se aprecia una reducción del tiempo necesario para solucionar los problemas más urgentes tras la inundación, respecto a eventos de repercusiones comparables en siglos pasados, como el analizado de la riada de San Calixto.

El análisis de la documentación muestra que en la magnitud de este desastre se solaparon un gran incremento de la exposición con una ausencia de mejoras en los sistemas de defensa, mitigación o prevención. Baste señalar que de los 19.320 habitantes de la ciudad de Murcia en 1755 se pasó a 29.949 en 1887. En este mismo período la población de

26. Noticias de El Diario de Murcia de 7 de diciembre de 1879. Fuente original mecanografiada (Murcia, AHPM).

27. Noticia de El Diario de Murcia de 7 de enero de 1880. Fuente original mecanografiada (Murcia, AHPM). 
la Huerta de Murcia creció desde los 50.156 a los 74.873 habitantes (Marset Campos et al., 1981). No obstante, la nueva situación de racionalidad aplicada al conocimiento científicotécnico provocó una mejor consideración de la peligrosidad natural del evento. En este sentido, se señala como novedad que las pendientes de los relieves de la cuenca del Segura están en el origen de la gran inundación ocurrida. Conviene señalar que algunos académicos de la época responsabilizaban también a la deforestación como causa del incremento de las pérdidas (Echegaray, 1851; Rico Sinobas, 1851; Hernández, 1885; Diaz Cassou, 1887).

A pesar de los grandes daños, se puede concluir que la gestión de este gran evento de inundación fue mejor que durante las grandes riadas de siglos atrás, debido principalmente a la señalada mejora técnica y la política de inversión en infraestructuras.

Entre los sectores sociales afectados se aprecia una mayor diversidad social y consideraciones a nuevos colectivos en relación con las inundaciones anteriores. Sin embargo, es importante señalar que en este evento se evidencia que los impactos afectaron más gravemente a los sectores más desfavorecidos y desprotegidos (niños, ancianos, mujeres, jornaleros y pobres), que concentran la mayor parte de la información sobre los afectados.

Paralelamente, la queja social se vio en parte atenuada por la magnitud del desastre vivido en la ciudad, que desató una corriente de solidaridad y comprensión entre los afectados o, simplemente, la población quedó tan afectada por los daños ocurridos que resultaba poco realista la exigencia inmediata de responsabilidades. También hay que tener en cuenta el efecto de la manipulación política de la información publicada en los periódicos del momento.

En cuanto a las causas generales, la evidencia de los hechos hace que se culpe menos a la naturaleza y más a las acciones del ser humano, aunque no tanto como se debiera dados los avances técnicos y el nuevo paradigma científico decimonónico. De nuevo, la manipulación informativa explica esta situación, puesto que los periódicos murcianos señalan a los pobres, agricultores y, en menor medida, al sistema de defensa y a los gestores y políticos como los principales responsables de la magnitud del desastre.

Las medidas de adaptación al riesgo de inundación en la ciudad de Murcia experimentan tras esta catástrofe un importante salto cualitativo. Los cambios administrativos, la mejora de las técnicas constructivas o la reedificación de viviendas en zonas menos expuestas son algunas de las nuevas soluciones consideradas. Sin embargo, muchas medidas no se llevaron a cabo de la forma apropiada por el conservadurismo de los poderes fácticos, lo que hizo que la actuación más importante continuase siendo la mejora de los sistemas de defensa frente a inundaciones, con respecto a la reducción de la exposición por invasión indebida de viviendas en el área inundable (Gil-Guirado, 2017).

\section{Infraestructuras de defensa frente $a$ inundaciones en la Huerta de Murcia}

La Huerta de Murcia y el crecimiento de la ciudad se han desarrollado de forma coetánea al desarrollo de soluciones a los problemas derivados de la naturaleza hidrológica del río 
Segura, esto es, a los extremos hidrológicos de este curso fluvial. En función de las posibilidades tecnológicas, secularmente se han ido desarrollando políticas de saneamiento y rectificación del curso del río. Estas políticas tomaron impulso entre los siglos xv al xIx (Roselló Verger y Cano García, 1975). Paralelamente a la ampliación del sistema de riesgo, el crecimiento del poblamiento estable obligó a tomar conciencia del mayor riesgo de inundación derivado de una creciente exposición. ${ }^{28}$ Comienzan a instalarse muros de contención, destacando el Trenque del Chillerón, el de Don Payo y, el más importante para la defensa de la ciudad de Murcia, el Muro del Malecón, construido en el siglo xv y reedificado en $1736 .{ }^{29}$ Esta última infraestructura se eleva $3 \mathrm{~m}$ sobre el nivel del suelo, rodeando la ciudad por su lado oeste en más de $1,5 \mathrm{~km}$. En la actualidad una parte considerable de ella aún supone la contención inmediata del agua del río a su paso por el centro de la ciudad. Existe amplia documentación sobre estas obras desde el siglo xvi, que revela que se llegaron a corregir siete grandes meandros del río entre 1593 y 1692, la mayor parte próximos a la ciudad de Murcia (Calvo García-Tornel, 1972).

Las alteraciones en la longitud del río Segura en el área de estudio dan cuenta de este proceso de «desmeandrización» del cauce, con un evidente cambio hacia una mayor linealidad a lo largo de los últimos dos siglos. Estos cambios se han realizado preferentemente en los meandros ubicados aguas arriba de la ciudad de Murcia y también en el tramo comprendido entre dicha ciudad y la pedanía de Alquerías (figura 5). Las cifras de este proceso de reducción de meandros hablan por sí solas. Si en 1810 la longitud de río Segura a su paso por la Huerta de Murcia era de 40.088 m, en 1879 esta cifra bajó hasta los 33.922 m, para descender hasta los 32.704 en el año 2019. Una reducción del $14 \%$ y del 18 \% respectivamente y que, en términos absolutos, indica que el Segura ha perdido más de $7 \mathrm{~km}$ en el área de estudio en los últimos dos siglos.

El propio sistema de riego es, a su vez, una amenaza para la población, por el factor de difusión de las crecidas que implica, pero también es concebido, por su organización y control estricto, como un sistema de defensa casi militar. Así, en 1706 durante la guerra de Sucesión española, el cardenal Belluga ordenó romper los diques de la contraparada para inundar la Huerta de Murcia e impedir que la ciudad de Murcia fuera tomada por las tropas leales a los Austrias. ${ }^{30}$ De forma similar, durante la guerra de Independencia española, los planes de defensa militar contemplaban la inundación controlada de la Huerta para evitar la entrada de las tropas napoleónicas (figura 6). Toda la red de riego de la Huerta de Murcia era concebida como un sistema de defensa integral frente a las amenazas externas. En este caso, amenaza de guerra.

El siglo xviI supuso un nuevo impulso a la defensa frente a inundaciones de la Huerta de Murcia. Calvo García-Tornel (1972) comenta que esta es la primera vez que se aborda la intención de solucionar el problema de las inundaciones de forma integral gracias a

28. Ordenanzas del Río de Sangonera de 1712. En Folletos Varios (núm. 15/23) (Murcia, AMM).

29. Actas Capitulares de la ciudad de Murcia de 6 de septiembre de 1732 y 7 de enero de 1738 . Fuente original manuscrita (Murcia, AMM).

30. Actas Capitulares de la ciudad de Murcia de 4 de septiembre de 1706. Fuente original manuscrita (Murcia, AMM). 


\section{Figura 5 \\ Cambios en el río Segura a su paso por la ciudad de Murcia en los últimos dos siglos}

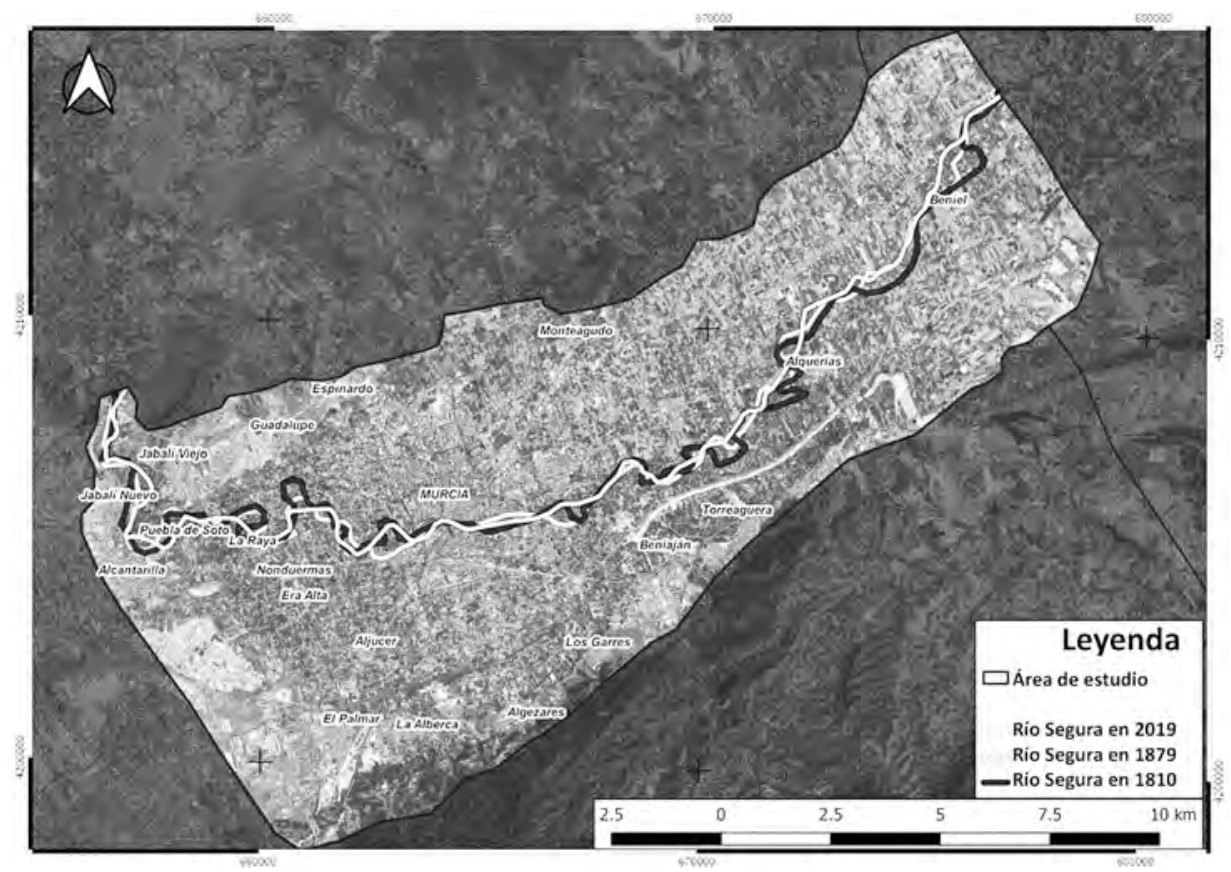

Fuentes: El cauce del río en 1810 está elaborado a partir del mapa de Pablo del Villar de 1810 (MECD, 2020), el cauce en 1879 está elaborado a partir del mapa de Juan Belando 1879 (Biblioteca Digital Hispánica, 2020), el cauce de 2019 está elaborado a partir de la imagen satelital del Plan Nacional de Ortofotografía Aérea (PNOA) de 2019 del Ministerio de Fomento, a través de la Dirección General del Instituto Geográfico Nacional (IGN) (2020).

la situación económica expansiva del período. Fue entonces cuando se construyó un canal artificial de derivación con el objetivo de desviar las erráticas y torrenciales inundaciones originadas por el río Guadalentín antes de su paso por la ciudad de Murcia. Es el llamado canal del Reguerón, aún hoy activo. Paralelamente, a finales de este siglo se comienza la construcción de los embalses de Puentes y Valdeinfierno en la cuenca alta del río Guadalentín, con la intención de aumentar la reserva de agua de riego para la vega de Lorca y disponer de una capacidad de embalse capaz de laminar las riadas de dicho cauce fluvial, principal amenaza para la ciudad de Murcia.

La falta de continuidad en las iniciativas técnicas, económicas, científicas y políticas hicieron mella en la estrategia de adaptación ante el riesgo de inundación. La crisis económica iniciada en la segunda mitad del siglo xviı supuso, según Pérez Picazo et al. (1980), un bloqueo tecnológico que impidió mejorar la adaptación de la sociedad al medio. No obstante, la ciencia y la técnica seguían de cerca las vicisitudes climáticas del siglo xix, ca- 
Figura 6

Sistema de riego de la Huerta de Murcia, estructura y posibles funciones defensivas: «Plano que manifiesta la Huerta de Murcia, preparada para ynundarla caso de ser amenazada de Ymbación la Capital, pr. 1s. Enemigs», Pablo del Villar, 1809

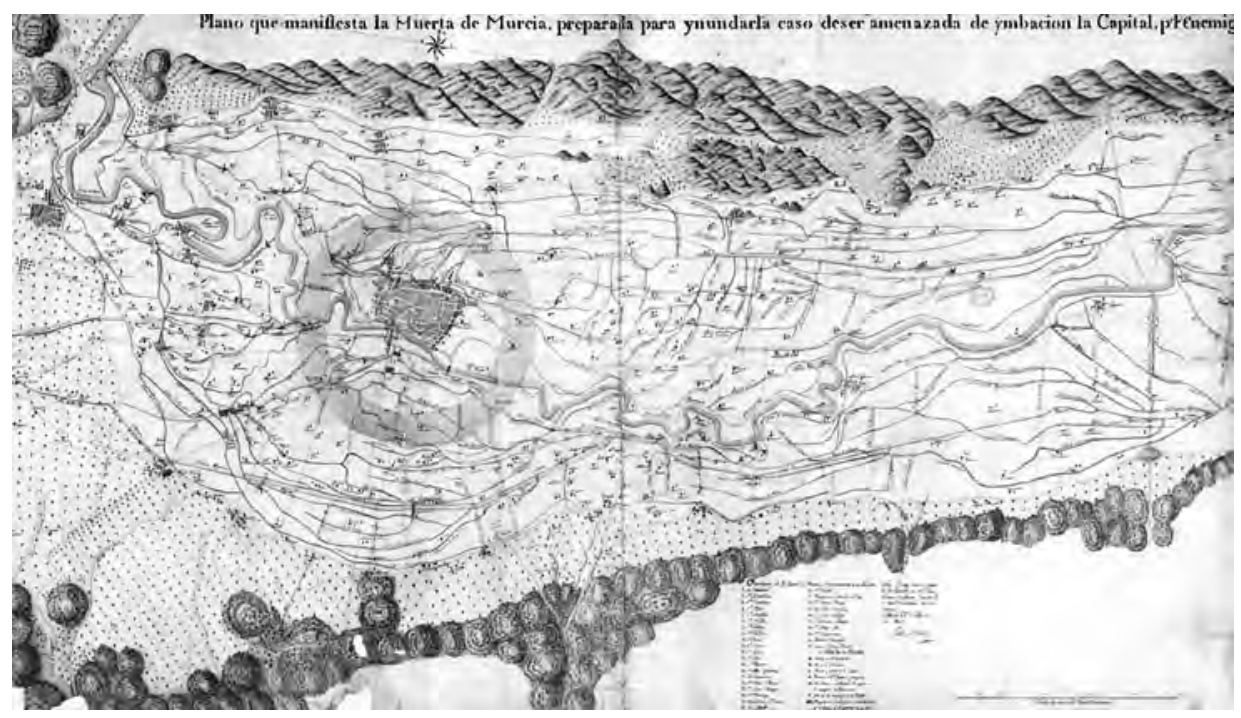

Fuente: MECD, 2020.

racterizado en el área de estudio por la alternancia de graves sequías y furiosas inundaciones (Gil-Guirado et al., 2019). En este último aspecto, tuvo mucho que ver la catástrofe ocasionada por la riada de Santa Teresa. La dimensión de la tragedia, unida a una nueva concienciación sobre la forma de enfrentarse al secular peligro de los ríos Segura y Guadalentín, influyeron en un cambio en la política hidráulica y en su impulso. El nuevo paradigma centró los esfuerzos en reforzar las márgenes del río y regular los afluentes del río Segura (especialmente el Guadalentín), al tiempo que se reformó el canal del Reguerón y se construyó un nuevo canal de derivación, el Paretón de Totana, con la finalidad de desviar las aguas del Guadalentín directamente hacia el mar (Calvo García-Tornel, 1972). A este respecto, la propia cartografía de la inundación de Santa Teresa evidenció que, a pesar de que la zona donde mayor altura tuvo la lámina de sedimentos, y por lo tanto la altura de la lámina de agua, fue en la antigua zona de confluencia del río Guadalentín con el río Segura (en las inmediaciones de las localidades de Nonduermas y Era Alta), el papel del canal del Reguerón fue determinante para limitar el impacto de la inundación dentro de la ciudad de Murcia. Sin embargo, las aguas derivadas del canal del Reguerón propiciaron grandes afecciones al este de la ciudad de Murcia, en torno a la localidad de Beniaján. Es decir, ya en 1879 el sistema de defensa frente a inundaciones en la Huerta de 
Murcia estaba diseñado para mitigar el riesgo en la ciudad central, en detrimento de las zonas rurales aledañas. Ello se ha podido corroborar al analizar cómo los daños ocasionados por esta riada fueron superiores en la huerta que en el centro urbano.

La supresión de meandros en torno a la ciudad de Murcia también manifiesta cómo el sistema de defensa frente a las inundaciones de la Huerta de Murcia se ha gestionado de forma radial, con el fin de mitigar el riesgo en el núcleo urbano a costa de transferir el peligro al entorno rural inmediato. Un hecho que encuentra su antecedente más notable en el propio trazado de la muralla medieval de la ciudad, concebida desde su génesis como un muro de protección frente a inundaciones.

\section{Conclusiones}

En análisis detallado de la documentación histórica demuestra que, al menos en el área de estudio, la generalización de los procesos de riesgo no es una consecuencia específica de la modernidad, tal como señala Beck (1998), sino que encuentra antecedentes históricos destacados en territorios y sociedades de riesgo como las mediterráneas. En estos casos, cobra sentido la afirmación de Giddens (2003), quien señaló que un fin principal del estado de bienestar es mitigar el riesgo a sus habitantes. En época moderna, según muestra la documentación analizada, la sociedad menos favorecida económicamente (agricultores) era dirigida en favor del beneficio de la oligarquía. Entre las clases pudientes, distintos subsectores intentaban adueñarse del favor del pueblo y ejercer así un poder sobre el resto de las clases dominantes, bajo la amenaza de usar al pueblo llano en su contra, pero nunca hasta el punto de poner en riesgo al propio sistema.

La investigación del análisis de la vulnerabilidad y el riesgo en distintos espacios y épocas evidencia la dificultad de los estudios en los que participan sistemas adaptativos socioecológicos complejos (Holland, 1995; Adger, 2006; Labbe, 2019). El interés particular por encima de la resolución real de los problemas es quizá la variable que dificulta el entendimiento completo de este proceso, puesto que, aun considerando que la sociedad en su conjunto pueda comportarse de manera adaptativa ante situaciones de emergencia o cambio, cuando las soluciones dependen de pocas personas se abandona el objetivo de alcanzar el óptimo ecosocial, para entrar en el impredecible terreno personal y psicológico.

El análisis crítico de los textos históricos muestra la idiosincrasia, potencialidades y debilidades de cada momento histórico. En consecuencia, debería tenerse en cuenta a la hora de planificar nuevos proyectos o escenarios de usos del agua, dado que permite identificar inercias con respecto a los sectores más afectados y, de esta manera, extrapolar los resultados a la actualidad de cara a alcanzar una óptima planificación territorial adaptada al grado de riesgo existente.

La intensidad del evento, las condiciones del poblamiento, la dinámica hidrológica y las particulares condiciones sociopolíticas y económicas ante el riesgo de inundación explican las diferencias que se producen entre eventos extremos ocurridos en diferentes siglos. La magnitud de las riadas hace que la gestión inmediata se vea impregnada por la 
improvisación, aunque a medida que pasan los siglos se observan mejoras a este respecto. El cambio comienza a producirse a partir del siglo xviI merced a la progresiva mejora en las infraestructuras hidráulicas. No obstante, la lentitud en la solución de los problemas ocasionados dejaba al sistema en una precaria situación ante nuevos eventos extremos causados por el funcionamiento espasmódico de las aguas del río Segura. De este modo, cuando se creían superados los efectos catastróficos de un evento extraordinario, tenía lugar otro.

El conocimiento, de una forma más o menos científica, de la génesis del problema de las inundaciones es una constante en la documentación consultada. Sin embargo, a la hora de afrontar las dificultades, no se llevan a cabo las medidas oportunas, porque los gestores del territorio se encuentran con una burocracia y pobreza económica que ralentiza la resolución de los problemas. A lo largo del período de estudio, se observa de forma constante en la documentación consultada el hecho de que las personas más vulnerables a menudo queden fuera de la toma de decisiones por su escasa participación en las estructuras de poder y limitado acceso a los recursos. Así, las políticas públicas de intervención para reducir la vulnerabilidad deben, por un lado, reconocer las características ambientales y, por otro, identificar las desigualdades e implicaciones sociales del riesgo para crear un marco favorable a una mayor resiliencia.

El análisis de la cartografía histórica ha permitido entender mejor los procesos de inundación en la ciudad de Murcia, así como una mejor caracterización y contextualización de cara a comprender la complejidad del área de estudio. La población era más vulnerable a las inundaciones en el período analizado que en la actualidad y se exponía de una forma menos adecuada, si bien es cierto que había sistemas complejos de protección frente a inundaciones como la propia muralla medieval de la ciudad. La muralla ha supuesto un muro defensivo frente a inundaciones al menos en los últimos cuatrocientos años. A este respecto, resulta curioso observar cómo las dos inundaciones más catastróficas para la ciudad de Murcia (San Calixto y Santa Teresa) se produjeron cuando la muralla ya no tenía funcionalidad.

El análisis de la documentación ha permitido entender mejor las contradicciones a las que se enfrenta una economía preindustrial agraria como la de la Huerta de Murcia (Pérez Picazo et al., 1980). Un sistema basado en el desarrollo del regadío, que supone la necesidad de ocupar un espacio llano donde la llegada del agua para riego sea cómoda, aun a sabiendas de que el peligro de inundación es constante (Calvo García-Tornel, 1972). De esta manera, el análisis de textos consultados ha permitido establecer lo que podríamos llamar «la paradoja del huertano». Esta se identifica como un modelo de ocupación del territorio que gira en torno a la contradicción de tener que exponerse al peligro de inundación, para poder prosperar económicamente, a pesar de que con más frecuencia de la deseable, la necesaria llegada de caudales para riego acabara incrementando el riesgo frente a inundaciones, cuyas frecuentes manifestaciones deprimían la economía de la zona. Con gran cotidianidad y estoicismo, la sociedad de la Huerta de Murcia asumía una nueva realidad consistente en convertirse en una población más pobre y miserable de lo que era tan solo unos meses antes de una inundación. 


\section{Bibliografía}

ADGER, W. N. (2006). Vulnerability. Global environmental change, vol. 16, núm. 3, pp. 268-281.

Alberola Romá, A. (1996). La percepción de la catástrofe: sequía e inundaciones en tierras valencianas durante la primera mitad del siglo xviI. Revista de Historia Moderna Anales de la Universidad de Alicante, núm. 15, pp. 257-269.

Alberola Romá, A. (1999). Catástrofe, economía y acción política en la Valencia del siglo xVIII. Valencia: Institució Alfons el Magnànim.

Alberola Romá, A. (2010a). El clima «trastornat»: sequera, temporals, riuades i inundacions a Catalunya i al País Valencià a les acaballes del segle xviI. Estudis d'Història Agrària, núm. 23, pp. 301-317.

Alberola Romá, A. (2010b). «Riadas, inundaciones y desastres en el sur valenciano a finales del siglo xviI». Papeles de Geografía, núm. 51-52, pp. 23-32.

Alberola Romá, A. (2014). Los cambios climáticos. La Pequeña Edad del Hielo en España. Madrid: Cátedra.

BARREDO, J. I. (2007). Major flood disasters in Europe: 1950-2005. Natural Hazards, vol. 42, núm. 1, pp. 125-148.

Barriendos, M.; Rodrigo, F. S. (2006). «Study of historical flood events on Spanish rivers using documentary data». Hydrological sciences journal, vol. 51, núm. 5, pp. 765-783.

Barriendos, M.; Gil-Guirado, S. et al. (2019). «Climatic and social factors behind the Spanish Mediterranean flood event chronologies from documentary sources (14th-20th centuries)». Global and Planetary Change, vol. 182, núm. 102997. Disponible en: https:// doi.org/10.1016/j.gloplacha.2019.102997

BECK, U. (2002). La sociedad del riego global. Madrid. Madrid: Siglo XXI.

Biblioteca Digital Hispánica (2020). Mapas antiguos. Biblioteca Nacional de España. Disponible en: http:/www.bne.es/es/Colecciones/GeografiaMapas/Subcolecciones/map_ antiguos.html (último acceso: 3 de junio de 2020).

Bıöschl, G.; Kiss, A. et al. (2020). «Current European flood-rich period exceptional compared with past 500 years». Nature, núm. 583, pp. 560-566. Disponible en: https://doi. org/10.1038/s41586-020-2478-3

Botrel, J. F. (2019). «Paris-Murcie, París-Murcia, Murcia-París: la presse et la charité sans frontières, en France et en Espagne, en 1879». Çédille: Revista de Estudios Franceses, núm. 16, pp. 101-114.

Brazdil, R.; Demaree, G. R. et al. (2019). «The extreme drought of 1842 in Europe as described by both documentary data and instrumental measurements». Climate of the Past, núm. 15, pp. 1861-1884. Disponible en: https://doi.org/10.5194/cp-15-1861-2019

BRAzDIL, R.; KISS, A. et al. (2018). «Documentary data and the study of past droughts: a global state of the art». Climate of the Past, núm. 14, pp. 1915-1960. Disponible en: https:// doi.org/10.5194/cp-14-1915-2018.

Brooks, N.; Adger, W. N.; Kelly, P. M. (2005). «The determinants of vulnerability and adaptive capacity at the national level and the implications for adaptation». Global Environmental Change, núm. 15, pp. 151-163. 
Calvo García-Tornel, F. (1969). «La huerta de Murcia y las avenidas del Guadalentín». Papeles de Geografía, núm. 1, pp. 11-137.

Calvo García-Tornel, F. (1972). «La formación del paisaje agrario de la huerta de Murcia». Revista de Geografía, núm. 6, pp. 5-33.

Calvo García-Tornel, F. (1997). «Algunas cuestiones sobre geografía de los riesgos». Scripta Nova, Revista Electrónica de Geografía y Ciencias Sociales, núm. 10. Disponible en: http://www.ub.edu/geocrit/sn-10.htm (último acceso: 2 de mayo de 2009).

Calvo García-Tornel, F. (2001). Sociedades y territorios en riesgo. Barcelona: Ediciones del Serbal.

Carles, R. (1879). La riada de Santa Teresa, 15 de octubre de 1879. Historia y detalles de esta horrorosa catástrofe. Murcia: Tip. de El Álbum. Disponible en: https://www. murcia.es/jspui/handle/10645/1619

Cascales, F. (1621). Discursos históricos de la mui noble i mui leal ciudad de Murcia y su reino. Murcia: Benedito.

Colten, C. E. (1991). «A historical perspective on industrial wastes and groundwater contamination». The Geographical Review, vol. 81, núm. 2, pp. 215-228.

CutTer, S.; Finch, C. (2007). «Temporal and Spatial changes in social vulnerability to natural hazards». PNAS, vol. 105, núm. 7, pp. 2301-2306.

Dauphine, A. (2001). Risques et catastrophes. Observer, spatialiser, comprendre, gérer. París: Armand Colin.

Diaz Cassou, P. (1887). La buerta de Murcia, su topografía, geología, climatología; descripción de sus sistemas de riego y saneamiento y de cada uno de los cauces que constituyen dichos sistemas. Régimen general de la buerta de Murcia y especial de cada uno de sus heredamientos. Madrid: Imp de Fontanet.

ECHEGARAY, J. de (1851). Memoria sobre las causas de la sequía de las provincias de Almería y Murcia, y de los medios de atenuar sus efectos, escrita con arreglo al programa del real decreto de 30 de marzo de 1850. Madrid: Imprenta del Ministerio de Comercio, Intrucción y Obras Públicas.

EndField, G. H. (2007). «Archival explorations of climate variability and social vulnerability in colonial Mexico». Climatic Change, vol. 83, núm. 1-2, pp. 9-38. Disponible en: https:// doi.org/10.1007/s10584-006-9125-3.

García Antón, J. (1993). Las murallas medievales de Murcia. Murcia: Universidad de Murcia-Real Academia Alfonso X el Sabio.

García Torres, A. (2017). «Extremismo climático y peligro biológico en el sureste español (1780-1800)». Revista de Historia Moderna. Anales de la Universidad de Alicante, núm. 35, pp. 345-376.

García Torres, A. (2018). Riesgo climático y desastre en tierras meridionales valencianas durante el siglo xviII. Alicante: Publicacions de la Universitat d'Alacant.

GidDEns, A. (2003). Un mundo desbocado. Madrid: Taurus.

GiL-Guirado, S. (2017). «Deconstruyendo riesgos. Cuatro siglos de cambios en la vulnerabilidad y adaptación a las inundaciones y sequías en Murcia». Revista de Historia Moderna. Anales de la Universidad de Alicante, núm. 35, pp. 308-344. 
Gil-Guirado, S.; Espín-Sánchez, J. A.; Prieto, M. del R. (2016). «Can we learn from the past? Four hundred years of changes in adaptation to floods and droughts. Measuring the vulnerability in two Hispanic cities». Climatic change, vol. 139, núm. 2, pp.183-200.

Gil-Guirado, S.; Gómez-Navarro, J. J.; Montávez, J. P. (2019). «The weather behind wordsnew methodologies for integrated hydrometeorological reconstruction through documentary sources». Climate of the Past, vol. 15, núm. 4, pp. 1303-1325.

Gil-Guirado, S.; Pérez-Morales, A. (2019). «Variabilidad climática y patrones termopluviométricos en Murcia (1863-2017): Técnicas de análisis climático en un contexto de cambio global». Investigaciones geográficas, núm. 71, pp. 27-54.

Gil Olcina, A. (1968). «El régimen del río Guadalentín». Saitabi, núm. 18, pp. 163-182.

Glaser, R.; Himmelsbach, I.; Bösmeier, A. (2017). «Climate of migration? How climate triggered migration from southwest Germany to North America during the 19th century». Climate of the Past, núm. 13, pp. 1573-1592. Disponible en: https://doi.org/10.5194/cp13-1573-2017.

Glaser, R.; Kahle, M. (2020). «Reconstructions of droughts in Germany since 1500- combining hermeneutic information and instrumental records in historical and modern perspectives». Climate of the Past, núm. 16, pp. 1207-1222. Disponible en: https://doi. org/10.5194/cp-16-1207-2020

Glaser, R. ; Riemann, D. ; Schönbein, J. et al. (2010). «The variability of European floods since AD 1500». Climatic Change, vol. 101, núm. 1-2, pp. 235-256. Disponible en: https:// doi.org/10.1007/s10584-010-9816-7.

Grinsted, A.; Moore, J. C.; Jevrejeva, S. (2012). «Homogeneous record of Atlantic hurricane surge threat since 1923». PNAS, vol. 109, núm. 48, pp. 19601-19605.

HERnÁNDEZ, A. (1885). Inundaciones de la buerta de Murcia. Juicio sobre su frecuente repetición de pocos años a esta parte; sus terribles desastres, sus causas y remedios. Murcia: Imprenta de El Diario.

Holland, J. (1995). Hidden Order: How Adaptation Builds Complexity. MA: Addison-Wesley, Reading.

Lopez Bermúdez, F. et al. (1981). «Inundaciones catastróficas, precipitaciones torrenciales y erosión en la provincia de Murcia». Papeles del Departamento de. Geografía, núm. 8, pp. 49-91.

IGN (2020). Plan Nacional de Ortofotografía Aérea (PNOA). Disponible en: https://pnoa. ign.es/ (último acceso: 20 de junio de 2020).

iPCC-Masson Delmotte, V.; Zhai, P.; Pirani, A.; Connors, S. L.; Péan, C.; Berger, S. et al. (eds.). (2021). Climate Change 2021: The Physical Science Basis. Contribution of Working Group I to the Sixth Assessment Report of the Intergovernmental Panel on Climate Change. Cambridge: Cambridge University Press [en prensa].

LabBÉ, T. (2019). «Aux origines des politiques compassionnelles: Émergence de la sensibilité envers les victimes de catastrophes à la fin du Moyen Âge». Annales. Histoire, Sciences Sociales, vol. 74, núm. 1, pp. 45-71.

Marset Campos, P. ; Chacón Jímenez, F. ; Lemeunier, G. et al. (1981). La sociedad murciana y cartagenera y las epidemias durante los siglos xvit, xviII y xix. En: Torres Fontes, J.; CASAL 
Martínez, F.; Mula Gómez, A. J. et al. De Historia Médica Murciana. II. Las epidemias. Murcia: Academia Alfonso X el Sabio, pp. 209-248.

MECD (2020). Cartografía de la Guerra de la Independencia. Disponible en: http://bvpb. mcu.es/cartografia/es/micrositios/busqueda.cmd (última revisión: 20 de julio de 2020).

Messerli, B.; Grosjean, M.; Hofer, T.; Nunez, L.; Pfister, C. (2000). «From nature-dominated to human-dominated environmental changes». Quaternary Science Reviews, vol. 19, núm. 1-5, pp. 459-479.

Nash, D.; Klein, J.; Endfield, G. H.; Pribyl, K.; Adamson, G. C.; Grab, S. W. (2019). «Narratives of nineteenth century drought in southern Africa in different historical source types». Climatic Change, vol. 152, núm. 3-4, pp. 467-485.

O'Brien, M.; Holland, T. (1992). «The role of adaptation in archeological explanation». American Antiquity, núm. 57, pp. 36-69.

Olcina Cantos, J. (2008). «Cambios en la consideración territorial, conceptual y de método de los riesgos naturales». Scripta Nova. Revista Electrónica de Geografía y Ciencias Sociales, vol. 12, núm. 270 (24). Disponible en: http://www.ub.es/geocrit/sn/sn-270/ sn-270-24.htm

Paris-MURCie (1879). París: Comité de Prensa Francesa. Disponible en: https://archivogeneral. carm.es/archivoGeneral/arg.detalle_documento?idDetalle $=2743283$

Pérez Picazo, M. T.; Lemeunier, G.; Chacón, F. (1980). Materiales para una historia de Murcia en los tiempos modernos. Murcia: Universidad de Murcia.

PérezMorales, A.; GilGuirado, S.; Olcina Cantos, J. (2018). «Housing bubbles and the increase of flood exposure. Failures in flood risk management on the Spanish southeastern coast (1975-2013)». Journal of Flood Risk Management, núm. 11, pp. S302-S313.

Pfister, C. (2011). «The Monster Swallows You. Disaster Memory and Risk Culture in Western Europe, 1500-2000». RCC Perspectives, núm. 1, pp. 1-23.

Pita, M. F.; Olcina Cantos, J. (2000). «Riesgos naturales, disciplina geográfica de futuro». Prólogo de número monográfico riesgos naturales. Boletín de la AGE, núm. 30, pp. 3-8.

Prieto, M. R.; García Herrera, R. (2009). «Documentary sources from South America: Potential for climate reconstruction». Palaeogeography, Palaeoclimatology, Palaeoecology, vol. 281, núm. 3-4, pp. 196-209.

Prieto, M. R.; Rojas, F. (2012). «Documentary evidence for changing climatic and anthropogenic influences on the Bermejo Wetland in Mendoza, Argentina, during the 16th-20th century». Climate of the Past, núm. 8, pp. 951-961. Disponible en: https://doi.org/10.5194/ cp-8-951-2012.

Prieto, M. R.; Rojas, F. (2015). «Determination of droughts and high floods of the Bermejo River (Argentina) based on documentary evidence (17th to 20th century)». Journal of Hydrology, núm. 529, pp. 676-683.

QGIS Development Team. (2016). QGIS geographic information system.

RAsHid, H. (2011). «Interpreting flood disasters and flood hazard perceptions from newspaper discourse: Tale of two floods in the Red River valley, Manitoba, Canada». Applied Geography, vol. 31, núm. 1, pp. 35-45. 
Rico Sinobas, M. (1851). Memoria sobre las causas meteorológico-físicas que producen las constantes sequías de Murcia y Almería. Madrid: Ministerio de Comercio.

Ros Sempere, M.; García Martín, F. M. (2012). «Análisis de la transformación de usos del suelo en la Huerta de Murcia: etapas, patrones de transformación y causas». En: CONAMA 2012, Congreso Nacional de Medio Ambiente, pp. 2-27. ISBN 9788469563779.

Roselló Verger, V.; Cano García, G. M. (1975). Evolución urbana de la ciudad de Murcia (831-1973). Murcia: Ayuntamiento de Murcia.

Smit, B.; Wandel, J. (2006). «Adaptation, adaptive capacity and vulnerability». Global environmental change, vol. 16, núm. 3, pp. 282-292.

Torres Fontes, J.; Calvo García-Tornel, F. (1975). «Inundaciones en Murcia (siglo xv)». Papeles de Geografía, núm. 6, pp. 29-49.

Torres Fontes, J.; Perea y Gómez, A. (1962). «La Riada de Santa Teresa del año 1879». Murgetana, núm. 18. Murcia: Real Academia Alfonso X, pp. 25-69.

Villevieille, A. (coord.). (1997). Les risques naturels en Méditerranée. Situation et perspectives. París: Les Fascicules du Plan Bleu. 